\title{
FREQUENT EPISODIC TENSION-TYPE HEADACHE IN STUDENTES OF PHYSIOTHERAPY COURSE
}

\author{
Élcio Alves Guimarães¹, Kennedy Rodrigues Lima², Mariana Nunes Faria², Kelly Duarte Lima Makhoul³, \\ Lucas Resende Sousa ${ }^{4}$, Paulo Cézar Simamoto Junior ${ }^{5}$, Gilmar da Cunha Sousa ${ }^{6}$, Alfredo Júlio Fernandes Neto ${ }^{5}$
}

\begin{abstract}
Introduction: Frequent episodic tension-type headache (FETTH), is described as frequent episodes of pain, located on both sides of the head, as a feeling of pressure or tightening, from mild to moderate intensity which may last from 30 minutes to seven days. The pain does not worsen with routine physical effort and may present photophobia or phonophobia. In this case, headache is one of the most common reasons for the complaint of children and adolescents, and it is a major problem among college students because it leads to the loss of study days and a decrease in academic performance. Objective: The aim of the present study was to conduct a survey on the prevalence of FETTH in students of Physiotherapy course of Centro Universitário do Triângulo (Unitri). Method: The research was done with the students registered in Physiotherapy course, in the second half of 2015, from the application of a questionnaire about the International Classification of Headache, according to the diagnostic criteria for FETTH. Result: Among the students, 18 (7.5\%) presented FETTH, based on these classification criteria, but it was expected that $50 \%$ of the students expose symptoms indicative of TTHEF. Conclusion: It is concluded that FETTH is a type of headache that is not very prevalent in the academic context of the Physiotherapy course of the referred institution.
\end{abstract}

Keywords: Headache, Students, Physiotherapy.

\section{INTRODUCTION}

Tension-type headache (TTH) is a common headache and it is a disease of great importance in relation to its socioeconomic impact. Headaches are considered the main reason for medical consultations, either in primary care units or in neurological clinics ${ }^{(1,2)}$.

Frequent episodic tension-type headache is described as frequent episodes of pain, located on both sides of the head, such as a feeling of pressure or tightness, the intensity of the pain may be mild to moderate and it may last from 30 minutes to seven days. The pain does not worsen with routine physical exertion such as walking or go up and down stairs and may present with photophobia or phonophobia ${ }^{(3,4)}$.

Instead of pulsating type pain on one side of the head as occurs in migraine, or even the periorbital intense pain which it is found in headache in salvos, the patients affected by the TTH report the pain as a pressure or tightening on both sides of the head. Characterized by the absence of nausea and vomiting as present in migraine, it presents photophobia or phonophobia, however in the presence of both symptoms, the diagnosis of TTH is eliminated ${ }^{(5)}$.
Different observational studies report that TTH affects a large part of the population. And by correlating the TTH with other pathologies and the dysfunctions that it may generate, it is considered a huge cost-related health problem for both society and individuals(6).

The headaches are among the top ten and most likely among the five causes of disability in the world. And the annual rates for headaches in general may vary between $46 \%-70.6 \%$. Among the primary headaches, TTH has the highest prevalence with $29.5 \%$ to $42 \%$, followed by migraine with $11 \%$ to $15.8 \%$ and chronic daily headaches with annual indices of 3 to $6.1 \%^{(7,8)}$.

It was supposed that the pain of TTH would be due to an exaggerated contracture of the musculature of the head, neck, shoulders, to the face, which would lead to a muscular ischemia and that would release algogenic substances which provoke the sensation of pain. According to some authors, the sustained contraction of the head and neck musculature would be the primary source of TTH pain, because when the tendons are stiffened due to some tension and stress,

Corresponding author: Élcio Alves Guimarães Av Dos Vinhedos, n. : 900 Bairro: Morada da Colina Uberlândia - Minas Gerais - Brazil CEP 38411 -159 +55 (34) 99687-4951 E-mail: elcio@unitri.edu.br

1. Physiotherapist, PhD student in Dentistry, Faculty of Dentistry, Federal University of Uberlândia (UFU), Uberlândia, - Minas Gerais - Brazil. Full list of author information is available at the end of the article.

Financial Support: none

Submission date 20 June 2017; Acceptance date 10 September 2017; Publication date 09 October 2017 
physiological mechanisms demand a greater supply of blood to nourish the muscles which are in sustained contraction, however that supply of blood may not be enough, through sustained contraction of the muscles, thus resulting in muscle ischemia which would result in the onset of pain, and also the constant contraction of muscle or the nervous supply may lead to release of harmful substances such as serotonin, bradykinin and prostaglandin, substances which increase painful sensation $^{(9)}$.

The TTH may occur due to several factors, and many studies have shown high sensitivity in pericranial myofascial tissues. The TTH is characterized by increased sensitivity to pain as well as increased frequency and intensity of pain, which are not found in patients with migraine ${ }^{(10)}$.

We must also consider the peripheral mechanisms that also play an important role in $\mathrm{TTH}$, since the prolongation of the entrance of peripheral nociceptive stimuli was mentioned by increasing the sensitivity on the peripheral pain through the sensitization of the central mechanisms ${ }^{(11)}$.

A study reported that in $74 \%$ of its sample, composed of university students, the headache is a prevalent and important problem as it leads to the loss of study days and a decrease in the academic performance. According to these authors that may be explained due to the high level of stress in which the students are exposed, caused because of university activities $^{(12)}$.

In students and adolescents, the prevalence of TTH is $10 \%$ to $25 \%$. And in a recent review, regarding 64 cross-sectional studies of 32 different countries, conducted in the last 25 years, totaling 227,249 children and adolescents, an overall mean prevalence of headache was estimated at $54.4 \%$ and a general average prevalence for migraine of $9.1 \%{ }^{(13,14)}$.

TTH is the most common headache and is a painful condition throughout the world, however throughout history it has been ignored in research. It may range from a mild and rare condition to a chronic, severe and disabling condition. TTH has received less attention regarding its similarity to migraine, even though in more severe and complicated headaches both may occur simultaneously. The low importance given to TTH probably comes from the historical view of it as a psychologically based disease and also due to the fact that in almost all cases it is milder conditions of TTH and does not cause damage ${ }^{(15)}$.

Therefore, the aim of this study was to evaluate the prevalence of frequent episodic of TTH in students of the Physiotherapy Course of the University Center of Triângulo-UNITRI.

\section{METHODOLOGY}

A field survey was carried out with 240 undergraduate students, men and women over 18 years old, in the Physiotherapy Course at the University Center of Triângulo (UNITRI) - full time - from September to October 2015.
Students under 18 years old were not included in the sample as well as those who were not found in the classroom during the period of data collection, those who did not sign the Free and Informed Consent Term and those who were not properly enrolled in the Course.

Thus, a questionnaire was applied according to the International Classification of Headache criteria - 3rd edition (CIC-III beta, 2013). Since it is a quantitative study, after the application of the tool, a classification of individuals classified as frequent episodic tension-type headache was done.

Data collection was carried out within the classrooms, in block $\mathrm{C}$ of the institution, at a time suitable for completing the questionnaire and with the prior authorization of the course manager and the teacher present at the place. At the moment of the approach, the student was explained the purpose of the study and, after showing interest, the student signed the Informed Consent Term, in which the objectives of the present study are documented. The questionnaire has 26 objective questions related to: frequency of seizures, type of pain, site, factors which trigger seizures and duration of headache. It is noteworthy that the cited instrument could be answered with a blue or black ballpoint pen with a time limit of 10 minutes to fill it.

After the questionnaire was applied, the data were tabulated for the screening of the answers by the following records: at least 10 crises occurring on 1 or more days per month, but less than 15 days per month (12 or more days per year); headache lasting from 30 minutes to seven days; headache with at least two of the following characteristics: bilateral location, character in pressure/tightness (non-pulsatile), mild or moderate intensity, or not aggravation by routine physical activity, such as walking or climbing stairs; absence of nausea or vomiting (possibility of anorexia), photophobia or phonophobia (only one of them may be present); not attribution to another disorder. Subsequently, such symptoms were classified as frequent episodic tension-type headache, according to the criteria mentioned above.

It should be noted that the present study did not offer physical risks. To avoid any embarrassment on the part of the volunteer due to doubts regarding the completion of the questionnaire, the researcher was present throughout the data collection.

All participants in the study have received two copies of the Term of Consent, pursuant to Resolution n. 466/2012 of the National Health Council (CNS, 2012). Each of the respondents received a copy of the document, while the other remained with the researcher. The project was sent to the Research Ethics Committee of the University Center of Triângulo-UNITRI, and was approved under protocol 1,198,173.

\section{RESULTS}

Among the 240 questionnaires applied to students of the UNITRI Physical Therapy course, 18 (7.5\%) presented frequent episodic tension-type headache (FETTH), based on 
the following criteria: frequency of attacks, length of headache duration, head location which usually hurts, type of pain, intensity of pain, factors which aggravate the pain and the symptoms which accompany the headache. From 18 students with FETTH, 17 (94.44\%) were females and 1 (5.56\%) was male. The age of students with FETTH ranges from 18 to 30 years, with a mean of approximately 21 years.

It can be seen from Table 1 that despite the age range being 18 to 30 years, as described previously, $61.11 \%$ of them are aged up to 21 years. Only 2 students, equivalent to $5.55 \%$, are at least 25 years old and at most 30 years old.

Table 1 - Frequency distribution and cumulative frequency with respect to the age of the students who presented FETTH.

\begin{tabular}{ccc}
\hline Age classes & Number & Frequency \\
\hline $18-21$ & 11 & $61.11 \%$ \\
$21-23$ & 2 & $11.11 \%$ \\
$23-25$ & 3 & $16.66 \%$ \\
$25-26$ & 1 & $5.55 \%$ \\
$28-30$ & 1 & $5.55 \%$ \\
Total & 18 & $100 \%$ \\
\hline
\end{tabular}

Table 2 - Distribution of frequencies and percentages of answers issued by the students, regarding the analyzed questions and total results.

\begin{tabular}{|c|c|c|}
\hline HEADACHE & $\mathbf{n}$ & $\%$ \\
\hline \multicolumn{3}{|l|}{ Frequency } \\
\hline Between 4 and 11 crises per year & 8 & $44.44 \%$ \\
\hline Between 1 and 7 days per month & 10 & $55.56 \%$ \\
\hline \multicolumn{3}{|l|}{ Duration } \\
\hline Less than 2 hours & 11 & $61.11 \%$ \\
\hline Less than 4 hours & 6 & $33.33 \%$ \\
\hline 4 to 24 hours & 1 & $5.56 \%$ \\
\hline \multicolumn{3}{|l|}{ Place of pain } \\
\hline Only one side of the head & 3 & $16.67 \%$ \\
\hline In the neck & 1 & $5.56 \%$ \\
\hline From the two sides of the head & 8 & $44.44 \%$ \\
\hline The whole head & 6 & $33.33 \%$ \\
\hline \multicolumn{3}{|l|}{ Type of pain } \\
\hline Throbbing, pulsatile like a heart beating & 10 & $55.56 \%$ \\
\hline In stitches, pricked & 1 & $5.56 \%$ \\
\hline Like a weight on top of the head & 5 & $27.78 \%$ \\
\hline Pressure, such as a tightening of the head & 2 & $11.11 \%$ \\
\hline \multicolumn{3}{|l|}{ Symptoms } \\
\hline The light bothers & 10 & $55.56 \%$ \\
\hline The noise bothers & 6 & $33.33 \%$ \\
\hline The eye turns red & 1 & $5.56 \%$ \\
\hline The watery eye & 1 & $5.56 \%$ \\
\hline
\end{tabular}

As shown in Table 2, 10 (55.56\%) students with FETTH had headache episodes ranging from one to seven days per month, while eight (44.44\%) had between four and eleven headache episodes per year. Concerning duration of pain, 11 (61.11\%) of the students with FETTH presented painful episodes with duration $<2$ hours, six $(33.33 \%)<4$ hours and one $(5.56 \%)$ had a headache from 4 to 24 hours. Regarding the site of the head that usually hurts during the painful episodes, eight (44.44\%) of the students with FETTH reported pain on both sides of the head. When asked about the type of pain, 10 (55.56\%) reported throbbing, pulsatile, heart-pounding pain, followed by pain on weight above the head, cited by five (27.78\%) of the students with FETTH. As for the associated symptoms, photophobia was reported by the majority of respondents 10 $(55.56 \%)$, considering that that symptom with the eye turning red and tearing, presented by one (5.56\%) student.

The percentage of students with FETTH (7.5\%) presented a result that was distant from the pre-established hypothesis. It was expected that at least $50 \%$ of the students would present symptoms suggestive of FETTH. Thus, the proportion test was performed to verify if through the acquired information, we could guarantee that the proportion of students with symptoms which indicate FETTH is significantly higher than $50 \%$.

Following are the analyzed hypotheses:

$$
\left\{\begin{array}{l}
H_{0}: p<50 \% \\
H_{1}: p \geq 50 \%
\end{array}\right.
$$

The unilateral to the right test was adopted with the significance level $\alpha=0,05$. The $p-$ valor was 1 . Therefore, weaccept the $H_{0}$ hypothesis since the $p-$ valor $>\alpha$. Which indicates that, with data from the sample, the established hypothesis that at least $50 \%$ of the students present symptoms indicative of FETTH, was violated at a significance level of $5 \%$. Which is, the proportion of students with symptoms that indicate FETTH is less than $50 \%$.

The range of $95 \%$ confidence interval for the proportion of students who have FETTH is $5.15 \%<p<100 \%$. The range of 95\% confidence interval for the proportion of students who have FETTH is. Which is, it is expected that in a sample of 100 students, at least 5 of them present TTHEF.

\section{DISCUSSION}

In a study in which migraine and tension-type headache were evaluated by means of the CIC - 3rd edition (CIC - III beta, 2013) in adolescents aged 12 to 19 years of a secondary school in Germany, a nine-day frequency of painful episodes in the last three months was observed for all students who had at least one episode of headache in the past six months ${ }^{(16)}$. This corroborates the present study, since 10 (55.56\%) of the students with FETTH have headache attacks from one to seven days per month, while eight (44.44\%) have between four and eleven headache crises per year. When analyzing the two samples, it is noticed that, in the study of the mentioned 
authors, there was a greater number of painful episodes in a smaller time space in relation to the students.

According to the present study in which $\mathrm{CIC}$ (2nd edition) was used, as an evaluation instrument, the duration of pain related to migraine and the TTH was 25 to 36 hours $^{(17)}$. Similarly, in the present study, we found that students with FETTH had painful episodes with a duration of less than two hours $(61.11 \%)$, less than four hours (33.33\%) and four to 24 hours (5,56\%), taking into consideration that TTHs may last from 30 minutes to seven days. Even if the time found in the mentioned study is not the same as in the present study, they meet the criteria for TTH according to $\mathrm{CIC}$.

The TTHs present as a classic sign the bilateral located pain. Thus, in a study in which 50 patients with TTH, it was found, as the most common location, the bilateral frontal pain, indicated by $40 \%$ of the participants ${ }^{(18)}$. This data corroborates the present research, although there are specific samples and types of FETTH, since the bilateral location was verified in $44.44 \%$ of the students with FETTH.

Meanwhile, a study shows that, in terms of the occurrence and the injuries of headache in university nursing students, the throbbing type pain was detected in $74.3 \%$ of the sample, however the type of headache that affected them was not specified $^{(19)}$. That, in a way, is in line with the present study, in which throbbing pain was observed in $10(55.56 \%)$ of the students with TTHEF.

In this context, they noted the prevalence of primary headache disorders in Fayoum Governorate, Egypt, through a structured questionnaire according to CIC-III beta (2013), to $553(45.3 \%)$ of the respondents, the pulsing-type pain is the most frequent ${ }^{(18)}$. Consistent with what was observed in the present study, in which 10 (55.56\%) of the students with FETTH had the same type of pain. Even though pressure or weight pain is common in TTHs, other characteristics highlighted by the students - frequency, intensity, duration, location of pain, aggravated or not with physical exercises and associated symptoms - were classified as FETTH by CIC-III beta.

The TTH is characterized by the presence of photophobia or phonophobia ${ }^{(3)}$. In the present study, 12 of 18 of the students with TTHEF had symptoms associated with photophobia (eye turns red or watery). And as described above in the study ${ }^{(20)}, 29.9 \%$ of respondents had photophobia and/or phonophobia, which corroborates with the present study, although they are different samples.

It should be noted that, patients already diagnosed with TTHE were evaluated through $\mathrm{CIC}$. The most frequent symptoms were nausea - 10 (20\%) of the sample -, followed by isolated photophobia - eight (16\%); and isolated phonophobia - six (12\%), in which four of the patients presented associated photophobia and phonophobia ${ }^{(18)}$. Such students have the opinion that when the clinical features of pain are very typical, the presence of combined photophobia and phonophobia does not compromise the diagnosis of TTH ${ }^{(18)}$.
In addition, in the aforementioned study it is affirmed that, although it is the most common form of cephalic pain of humanity, the TTH is not strongly studied. There are few studies which focus specifically on that type of pain, according to its clinical characteristics, the family history of headache and its impact on the work activities ${ }^{(18)}$.

\section{CONCLUSION}

It is concluded that FETTH is a type of headache that is not very prevalent among the academic environment in the Physiotherapy course.

\section{AUTHOR'S CONTRIBUTION}

All authors worked actively for the study, participating in all stages. The present article is linked to the Doctorate in Dentistry project - FOUFU by the doctoral student Élcio Alves Guimarães. Mariana Nunes Faria and Kennedy Rodrigues Lima participated as undergraduates and took the conclusion thesis from this article. Prof. MS Kelly D.L. Makhoul was a counselor of the student. Lucas Resende Sousa was guided as undergraduate student and participated in data collection and article writing. The Professors Paulo Cézar Simamoto Jr, Gilmar da Cunha Sousa and Alfredo Júlio Fernandes Neto are PhD and supervisors of the doctorate student Élcio Alves Guimarães. The whole group works cohesively and dynamically.

\section{CONFLICTS OF INTEREST}

The author(s) declare that they have no competing interests.

\section{AUTHOR DETAILS}

2. Physiotherapist, University Center of Triangulo (Unitri), Uberlândia - Minas Gerais - Brazil.

3. Physiotherapist, Professor of the University Center of the Triangulo (Unitri), Uberlândia - Minas Gerais - Brazil.

4. Physiotherapist, Master's degree student in Health Sciences at the Federal University of Uberlândia (UFU), Uberlândia - Minas Gerais - Brazil.

5. PhD Professor, Faculty of Dentistry, Federal University of Uberlândia (UFU), Uberlândia - Minas Gerais - Brazil.

6. PhD Professor, Institute of Biomedical Sciences, Federal University of Uberlândia (UFU), Uberlândia - Minas Gerais - Brazil.

\section{REFERENCES}

1 Palacios-Ceña M, Castaldo M, Wang K, Catena A, Torelli P, Arendt-Nielsen $L$, Fernández-de-las-Peñas $C$. Relationship of active trigger points with related disability and anxiety in people with tension-type headache. Medicine [internet]. 2017:96(13). Disponível em: https://www.ncbi.nlm. nih.gov/pmc/articles/PMC5380302/pdf/medi-96-e6548.pdf.

2 Dong Z, Yin Z, He M, Chen X, Lv X, Yu S. Validation of a guideline-based decision support system for the diagnosis of primary headache disorders based on ICHD-3 beta. J Headache Pain [internet]. 2014:15(1). Disponível em: https://www.ncbi.nlm.nih.gov/pmc/articles/PMC40 74417/.

3 Headache Classification Committee of the International Headache Society (IHS) The International Classification of Headache Disorders. 2013; 33(9): 629-808.

4 Subcomissão de Classificação das Cefaleias da Sociedade Internacional de Cefaleias (IHS). CLASSIFICAÇÃO INTERNACIONAL DE CEFALEIAS. 2013. Trad. Portuguesa. Sociedade Portuguesa de Cefaleias, 2014.

5 Weinman D, Nicastro O, Akala O, Friedman BW. Parenteral treatment of episodic tension-type headache: a systematic review. Headache. 2014:54: 260-268.

6 Taga A, Russo M, Manzoni GC, Torelli P. Tension-Type headache in Parma's adult general population: a focus on age of onset. Neurol Sci. 2015:36: 29-34. 
7 Mengistu G, Alemayehu S. Prevalence and burden of primary headache disorders among a local community in Addis Ababa, Ethiopia. J Headache Pain [internet]. 2013:14(1):30. Disponível em: https://www.ncbi.nlm.nih. gov/pmc/articles/PMC3620379/.

8 Conti PCR, Costa YM, Gonçalves DA, Svensson P. Headaches and myofascial temporomandibular disorders: overlapping entities, separe managements? Journal of Oral Rehabilitation. 2016:43:702-715.

9 Mendes MRP, Silva AN, Amaral JT. Uso da terapia manual e do alongamento em indivíduos com cefaleia tensional. Linkania rev. cient. [Internet]. 2014:1(7):102-159. Disponível em: http://linkania.org/master/ article/view/162/108.

10 Madsen BK, Søgaard K, Andersen LL, Skotte JH, Jensen RH. Neck and shoulder muscle strength in patients with tension-type headache: $A$ case-control study. Cephalalgia. 2016:36(1): 29-36.

11 Karadaş Ö, Gül HL, İnan LE. Lidocaine injection of pericranial myofascial trigger points in the treatment of frequent episodic tension-type headache. J Headache Pain [internet]. 2013:14(1):44. Disponível em: https://www.ncbi.nlm.nih.gov/pmc/articles/PMC3671170/.

12 Falavigna A, Teles AR, Braga GL, Conzatti LP, Ruschel LG, Silva PG. Association between primary headaches and depression in young adults in southern Brazil. Rev Assoc Med Bras. 2013:59(6):589-593.

13 Soee A-BL, Skov L, Kreiner S, Tornoe B, Thomsen LL. Pain sensitivity and pericranial tenderness in children with tension-type headache: a controlled study. J Pain Res. 2013:6:425-434.
14 Albers L, Straube A, Landgraf MN, Heinen F, von Kries R. High diagnostic stability of confirmed migraine and confirmed tension-type headache according to the ICHD-3 beta in adolescents. J Headache Pain [internet]. 2014:15(1):36. Disponível em: https://www.ncbi.nlm.nih.gov/pmc/ articles/PMC4075938/.

15 Rains JC, Davis RE, Smitherman TA. Tension-Type Headache and Sleep. Curr Neurol Neurosci Rep. 2015; 15(2): 520.

16 Albers L, Straube A, Landgraf MN, Filippopulos F, Heinen F, von Kries R. Migraine and tension type headache in adolescents at grammar school in Germany - burden of disease and health care utilization. J Headache Pain. [Internet] 2015:16:52. Disponível em: https://www.ncbi.nlm.nih. gov/pmc/articles/PMC4467810/.

17 Constantinides V, Anagnostou E, Bougea A, Paraskevas G, Kapaki E, Evdokimidis I, et al. Migraine and tension-type headache triggers in a Greek population. Arq. Neuropsiquiatr. 2015:73(8):665-669.

18 Matta APC, FILHO PFM. Cefaléia do tipo tensional episódica: avaliação clínica de 50 pacientes. Arquivo Neuropsiquiatr. 2006:64(1):95-99.

19 Braga PCV, Souza LAF, Evangelista RA, Pereira LV. Ocorrência e prejuízos da cefaleia em estudantes universitárias de enfermagem. Rev. Esc. Enferm. 2012:46(1):138-144.

20 EL-Sherbiny NA, Masoud M, Shalaby NM, Shehata HS. Prevalence of primary headache disorders in Fyoum Governorate, Egypt. J Headache Pain [Internet]. 2015:16:85. Disponível em: https://www.ncbi.nlm.nih. gov/pmc/articles/PMC4593989/. 